\title{
A Model for Static Recrystallization with Simultaneous Precipitation and Solute Drag
}

\author{
HEINRICH BUKEN and ERNST KOZESCHNIK
}

In the present work, we introduce a state parameter-based microstructure evolution model, which incorporates the effect of solute atoms and precipitates on recrystallization kinetics. The model accounts for local precipitate coarsening at grain boundaries, which promotes an average grain boundary movement even if the Zener pinning force exceeds the driving force for recrystallization. The impact of solute drag on the grain boundary mobility as well as simultaneous precipitation is discussed in detail. The model is validated on experimental data on recrystallization in V-micro-alloyed steel, where excellent agreement is achieved.

DOI: $10.1007 / \mathrm{s} 11661-016-3524-5$

(C) The Author(s) 2016. This article is published with open access at Springerlink.com

\section{INTRODUCTION}

DURING thermo-mechanical processing of crystalline materials, the growth velocity of recrystallizing grains can strongly be affected by the presence of precipitates and solute atoms. Precipitates interact with the moving grain boundaries via the well-known Zener pinning effect, ${ }^{[1]}$ which acts as a retarding force on the velocity of boundary movement. The magnitude of the Zener pressure is mainly determined by the precipitate phase fraction and size, which are commonly evolving in the course of thermo-mechanical treatment. In case of micro-alloyed steel, this effect is experimentally well analyzed for the case of carbo-nitrides forming with minor additions of $\mathrm{Al}, \mathrm{V}, \mathrm{Ti}$, and $\mathrm{Nb}^{[2]}$

In addition to Zener pinning, the grain boundary mobility can also be drastically influenced by the solute drag effect. ${ }^{[3]}$ In this case, elements that are segregated into the grain boundary must be "dragged along" with the moving boundary, thus exerting a retarding effect on the movement. The absolute value of the solute drag effect is mainly determined by the nominal concentration of the solute drag elements and their binding energy to the grain boundary. Detailed experiments in steel ${ }^{4]}$ show that $\mathrm{V}, \mathrm{Mo}, \mathrm{Ti}$, and $\mathrm{Nb}$ are probably the most practically relevant elements with regard to solute drag in austenite of Fe-based alloys. A proper consideration of both effects, Zener drag and solute drag, is therefore essential for a successful simulation of recrystallization kinetics.

In literature, two types of simulation approaches exist for a description of these effects in micro-alloyed steel: phenomenological and physically based models. On one

HEINRICH BUKEN, PhD Student, is with the Institute of Materials Science and Technology, TU Wien, Getreidemarkt 9, 1060 Vienna, Austria. Contact e-mail: heinrich.buken@tuwien.ac.at ERNST KOZESCHNIK, Professor, is with the Institute of Materials Science and Technology, TU Wien, and also with MatCalc Engineering $\mathrm{GmbH}$, Getreidemarkt 9, 1060 Vienna, Austria.

Manuscript submitted December 15, 2015.

Article published online April 27, 2016 hand, Medina and co-workers ${ }^{[2,5]}$ utilize a phenomenological approach based on the Avrami model. ${ }^{[6]}$ In this approach, the impact of precipitation on recrystallization is described by means of two coupled Avrami equations. The fast reaction term reproduces recrystallization kinetics in the regime before the Zener pressure exceeds the driving pressure for recrystallization. As soon as precipitation starts to control the grain boundary mobility, the slower Avrami kinetics becomes dominant. By interconnecting both solutions (slow and fast kinetics), Medina et al. are able to describe the evolution of the recrystallized fraction for a large amount of precipitation-controlled recrystallization experiments. The additional effect of solute atoms on grain boundary mobility is taken into account indirectly by an empiric formula, which accounts for the nominal chemical composition of the steel with a composition-dependent activation energy for recrystallization.

In contrast, Zurob et al. ${ }^{[7,8]}$ suggest a physically based approach, where the growth of recrystallized grains is expressed in terms of mobility and driving pressure. The impact of precipitation on growth kinetics is incorporated in the driving pressure term via the effective driving force resulting from the difference between recrystallization driving and Zener pinning pressure. This approach is well in line with former models suggested by Hillert ${ }^{[9]}$ and Nes. ${ }^{[10]}$ The solute drag impact in the Zurob et al. model is accounted for on the basis of the work of $\mathrm{Cahn}^{[3]}$ and it is, thus, included inherently in the grain boundary mobility.

In the present work, a comprehensive state parameter-based model coupling a multi-component multiphase framework for precipitation kinetics simulation with a physically based grain boundary movement and recrystallization approach including the impact of precipitation is introduced. The precipitation kinetics simulations utilize the comprehensive thermokinetic simulation environment MatCalc, where precipitation kinetics are computed as a function of temperature, deformation conditions and alloy compositions in a more or less fitting parameter-free manner. The 
successful applicability of MatCalc to precipitation problems in micro-alloyed steel has been demonstrated many times, see, for instance, References 11 and 12. The nucleation and growth models utilized in the precipitation kinetics simulations are described in detail in References 13 through 16 . The recrystallization model is introduced subsequently.

\section{THE MODEL}

\section{A. Recrystallization}

The evolution of the polycrystalline microstructure after deformation is expressed in terms of the nucleation and growth kinetics of recrystallized grains. The formation of recrystallization nuclei occurs on the junctions of high-angle grain boundaries (HAGB) and low-angle grain boundaries (LAGB) in the sense of the BaileyHirsch mechanism. ${ }^{[17]}$ For instance, the experimental results of Reference 18 confirm the occurrence of recrystallization nucleation at grain boundaries in low-alloyed steel. Consequently, the nucleation rate, $\dot{N}_{\text {rx }}$, is written as

$$
\dot{N}_{\mathrm{rx}}= \begin{cases}C_{\mathrm{rx}}\left(\frac{\pi}{6} \delta^{2} D\right)^{-1} \exp \left(\frac{-Q_{\mathrm{rx}}}{R T}\right)\left(1-X_{\mathrm{rx}}\right) & , \delta \geq \delta_{\text {crit }} \\ 0 & , \delta<\delta_{\text {crit }}\end{cases}
$$

where $\delta$ is the subgrain diameter, $D$ is the mean unrecrystallized grain diameter, $C_{\mathrm{rx}}$ is a calibration coefficient, $Q_{\mathrm{rx}}$ is an activation energy similar in value to that for substitutional self-diffusion along grain boundaries, $X_{\mathrm{rx}}$ is the recrystallized fraction, and $R$ is the universal gas constant. The parent austenite grain is assumed to be of spherical geometry. The criterion for nucleation is determined by the ratio between the surface energy of a subgrain, $\gamma_{\mathrm{LB}}$, and the driving force for recrystallization, $P_{\mathrm{D}}$, which is provided by the excess of deformation-induced dislocations. The corresponding relation ${ }^{[19]}$ reads as

$$
\delta_{\text {crit }}=\frac{3 \gamma_{\mathrm{LB}}}{P_{\mathrm{D}}}=\frac{3 \gamma_{\mathrm{LB}}}{0.5 G b^{2} \rho} .
$$

The energy contribution of dislocations is calculated via the shear modulus, $G$, the burgers vector, $b$, and the excess dislocation density $\rho$. Once the nucleus exceeds a critical size, its further growth rate, $\dot{D}_{\mathrm{rx}}$, is expressed in terms of an effective HABG mobility, $M_{\mathrm{eff}, \mathrm{HB}}$, and the driving force as

$$
\dot{D}_{\mathrm{rx}}=M_{\mathrm{eff}, \mathrm{HB}} P_{\mathrm{D}}\left(1-X_{\mathrm{rx}}\right) .
$$

In the course of recrystallization, the overall growth velocity of recrystallizing grains is assumed to decrease as a consequence of decreasingly available unrecrystallized volume. The evolution of the recrystallized fraction, which represents the ratio between the velocity of recrystallized volume gain, $\dot{V}_{\text {rx }}$, and total volume, $V_{\text {tot }}$, is expressed as superposition of a term related to the nucleation of newly recrystallized grains and growth of existing ones as

$$
\dot{X}_{\mathrm{rx}}=\frac{\pi}{6}\left(\dot{N}_{\mathrm{rx}} D_{\mathrm{rx}}^{3}+3 N_{\mathrm{rx}} \dot{D}_{\mathrm{rx}} D_{\mathrm{rx}}^{2}\right)=\frac{\dot{V}_{\mathrm{rx}}}{V_{\mathrm{tot}}} .
$$

The evolution of the dislocation density is described by means of an extended Kocks-Mecking model considering the processes of dislocation generation as well as dynamic and static recovery. In this context, we closely follow the approach introduced by Sherstnev et $a l .{ }^{[20]}$ describing the rate of the total dislocation density evolution as

$$
\dot{\rho}=\frac{M \sqrt{\rho}}{A b} \dot{\phi}-2 B \frac{d_{\mathrm{ann}}}{b} \rho M \dot{\phi}-2 C D_{\mathrm{Dis}} \frac{G b^{3}}{k_{B} T}\left(\rho-\rho_{\mathrm{RS}}\right),
$$

with the Taylor factor, $M$, the critical dislocation annihilation distance, $d_{\mathrm{ann}}$, the substitutional self-diffusion coefficient at dislocations, $D_{\text {Dis }}$, the strain rate $\dot{\phi}$, and material parameters $A, B$, and $C$. However, in contrast to the original Sherstnev et al. model, where the authors assume that the driving force for static recovery is given by the difference of actual and equilibrium dislocation density, we introduce a limiting degree of static recovery, here, given by the amount of geometrically necessary dislocations, $\rho_{\mathrm{RS}}$, for maintaining the subgrain microstructure. In the Read-Shockley model, ${ }^{[21]}$ which is adopted here, the mean subgrain misorientation angle, $\theta_{\text {mean }}$, and the mean subgrain size, $\delta$, in a periodic network in the grain boundary plane, define the required dislocation density, $\rho_{\mathrm{RS}}$, as

$$
\rho_{\mathrm{RS}}=\frac{\tan \left(\theta_{\text {mean }}\right)}{b \delta} .
$$

The deformation-induced subgrain size is assumed to be correlated with the dislocation density by means of the principle of similitude. ${ }^{[22,23]}$ This mainly empirical relation delivers a cell/subgrain size, which is directly linked to the dislocation density evolution during deformation with

$$
\delta=\frac{K}{\sqrt{\rho}},
$$

where $K$ is a material parameter. After deformation, and before the onset of recrystallization, subgrain coarsening takes place. The mean growth rate of subgrains is expressed in terms of an effective LAGB mobility, $M_{\text {eff,LB }}$, and a driving force provided by curvature

$$
\dot{\delta}=M_{\mathrm{eff}, \mathrm{LB}} \frac{3 \gamma_{\mathrm{LB}}}{\delta},
$$

with $M_{\text {eff,LB }}$ as an effective LAGB mobility.

The numerical integration of the presented microstructure evolution model is performed by the thermokinetic software tool MatCalc, which utilizes an automatic and adaptive time-step control. 


\section{B. Precipitates and Solute Atoms}

Micro-alloying elements in steel can have two effects on recrystallization kinetics: Zener pinning by carbo-nitride particles and solute drag by solid solution atoms. ${ }^{[7]}$ For the effect of precipitates, the Zener pressure, $P_{\mathrm{Z}}$, can be expressed ${ }^{[10]}$ as

$$
P_{\mathrm{Z}}=\frac{3 f \gamma_{\mathrm{HB}}}{2 r},
$$

with $f$ being the precipitated phase fraction and $r$ being the mean precipitate radius. Since the MatCalc precipitation kinetics framework offers detailed information on the size distribution of precipitates also, in the simulations, a size class-based formulation of the Zener pressure is used as introduced by Rath and Kozeschnik $^{[24]}$ in a recent treatment of coupled precipitation and grain growth. To account for different precipitate types, $i$, and size classes, $k$, we use the following expression which reads

$$
P_{\mathrm{Z}}(k, i)=\frac{3}{2} \gamma_{\mathrm{HB}} \sum_{i} \sum_{k} \frac{f_{k, i}}{r_{k, i}} .
$$

To describe the impact of precipitation on recrystallization, we assume that the precipitates, which potentially pin the boundaries, are interconnected along high-velocity diffusion paths, i.e., the grain boundaries. Due to the fast diffusion kinetics along the boundaries, the precipitates are subject to significantly accelerated coarsening. When the number density of precipitates pinning the boundary decreases due to coarsening, the Zener pressure decreases and the grain boundary becomes locally released. The free grain boundary then continues to move further into the deformed microstructure until it encounters a new front of pinning precipitates, where the local coarsening procedure repeats. On average, the grain boundary can thus continuously move through the material even if the Zener pressure determined by the initial precipitate distribution exceeds the driving pressure for recrystallization. This issue is discussed in detail in Reference 25.

In support of this concept, Yazawa et al. ${ }^{[26]}$ and Jones and Ralph ${ }^{[27]}$ experimentally observed this special precipitate coarsening behavior in the presence of recrystallization. The precipitates in front of the moving boundary and behind had significantly different average size and number density. To mimic this behavior in our model, we include the Zener pressure into the mobility term instead of reducing the available driving force by the Zener pressure to obtain an effective driving force. The resulting mobility taking into account the particle pinning effect reads as

$M_{\text {prec }}=\left\{\begin{array}{ll}\left(\frac{P_{\mathrm{D}}-P_{\mathrm{Z}}}{P_{\mathrm{D}}}\right) M_{\text {free }}+\left(1-\frac{P_{\mathrm{D}}-P_{\mathrm{Z}}}{P_{\mathrm{D}}}\right) M_{\text {pinned }} & , P_{\mathrm{D}}>P_{\mathrm{Z}} \\ M_{\text {pinned }} & , P_{\mathrm{D}} \leq P_{\mathrm{Z}}\end{array}\right.$,

where $M_{\text {prec }}$ is the effective mobility of the grain boundary in the presence of precipitates, $M_{\text {free }}$ is the free mobility without any dragging and retarding influences of particles and/or solute atoms, and $M_{\text {pinned }}$ is the limiting (non-zero) mobility, which is adopted by the grain boundary when the Zener pressure exceeds the driving pressure for recrystallization.

In the present model, the impact of solute drag is modeled on the basis of the work of Cahn. ${ }^{[3]}$ Accordingly, the dragging effect of solute atoms, which are segregated into the grain boundary, is incorporated into the mobility term with

$$
M_{\mathrm{SD}}=\frac{1}{\alpha C_{\mathrm{GB}}},
$$

where $M_{\mathrm{SD}}$ is the mobility of the grain boundary in the presence of solute drag, $C_{\mathrm{GB}}$ is the grain boundary concentration of the solute drag element, andais an inverse mobility. The latter determines the temperature dependency of the solute drag effect via the grain boundary/atom interaction energy, $E_{\mathrm{B}}$, given as

$$
\alpha=\frac{\omega(R T)^{2}}{E_{\mathrm{B}} D_{\mathrm{CB}} V_{\mathrm{M}}}\left(\sinh \left(\frac{E_{\mathrm{B}}}{R T}\right)-\left(\frac{E_{\mathrm{B}}}{R T}\right)\right),
$$

where $\omega$ is the grain boundary width, $V_{\mathrm{M}}$ is the molar volume of the matrix phase, and $D_{\mathrm{CB}}$ is the cross-boundary diffusion coefficient of the solute drag element. For convenience, in the present analysis, the grain boundary concentration is assumed to be identical to that of the matrix without any regard of additional element segregation into the boundary.

The integral effective mobility is finally evaluated as

$$
M_{\mathrm{eff}, \mathrm{HB}}=\left(\frac{1}{M_{\mathrm{prec}}}+\frac{1}{M_{\mathrm{SD}}}\right)^{-1},
$$

which is in accordance with Cahńs original suggestion of combining the solute drag mobility with the free mobility.

\section{Materials}

To validate the present model, we analyze the experimental observations on simultaneous recrystallization and precipitation reported by Medina et al., ${ }^{[28]}$ who measure the progress of static recrystallization after deformation. The selected materials have been investigated at different degrees of supersaturation, determined by the $\mathrm{V}$ and $\mathrm{N}$ content. The chemical composition, thus, also determines the solution temperature, $T_{\text {Sol }}$, listed in Table I, in addition to the starting grain size. The experiments are carried out in a temperature range between $1098 \mathrm{~K}$ and $1373 \mathrm{~K}\left(825{ }^{\circ} \mathrm{C}\right.$ and $\left.1100{ }^{\circ} \mathrm{C}\right)$. Since the aim of the present investigation is to model the influences of solute drag and Zener drag on recrystallization kinetics, we only vary parameters (temperature and composition), which are most important to these influences. Thus, the considered deformation parameters are a constant strain rate of $3.63 \mathrm{~s}^{-1}$ and a strain of 0.35 .

\section{Model Parameters}

Apart from the parameters $C_{\mathrm{rx}}$ and $Q_{\mathrm{rx}}$, Eq. [1], which determine the nucleation rate of recrystallizing grains, a 
Table I. Chemical Composition of Simulated Materials ${ }^{[32]}$

\begin{tabular}{|c|c|c|c|c|c|}
\hline ID. & V (Wt Pct) & C (Wt Pct) & N (Wt Pct) & $T_{\text {Sol }}(\mathrm{K})$ & $D_{0}(\mu \mathrm{m})$ \\
\hline V1 & 0.043 & 0.11 & 0.0105 & 1296 & 172 \\
\hline $\mathrm{V} 2$ & 0.06 & 0.12 & 0.0123 & 1331 & 167 \\
\hline V3 & 0.093 & 0.12 & 0.0144 & 1379 & 165 \\
\hline
\end{tabular}

Table II. Input Parameters for Recrystallization Simulation

\begin{tabular}{llll}
\hline Parameter & \multicolumn{1}{c}{ Value } & Unit & References \\
\hline$D_{\mathrm{Dis}}$ & $4.5 \times 10^{-5} \exp (185000 / R T)$ & $\mathrm{m}^{2} / \mathrm{s}$ & 34 \\
$D_{\mathrm{GB}}$ & $5.5 \times 10^{-5} \exp (145000 / R T)$ & $\mathrm{m}^{2} / \mathrm{s}$ & 34 \\
$D_{\mathrm{CB}}$ & $2 D_{\mathrm{B}}$ & $\mathrm{m} / \mathrm{s} / \mathrm{mol}$ & 36 \\
$Q_{\mathrm{rx}}$ & 145 & - & 34 \\
$C_{\mathrm{rx}}$ & $1.5 \times 10^{6}$ & $\mathrm{~J} / \mathrm{m}^{2}$ & This work \\
$\gamma_{\mathrm{HB}}$ & $1.3111-0.0005 T$ & $\mathrm{~J} / \mathrm{m}^{2}$ & 7 \\
$\gamma_{\mathrm{LB}}$ & $0.5 \gamma_{\mathrm{HB}}$ & - & This work \\
$A, B, C$ & $50 ; 5 ; 5 \times 10^{-5}$ & degree & This work \\
$K$ & $\mathrm{~A}$ & $\mathrm{~kJ} / \mathrm{mol}$ & This work \\
$\theta_{\text {mean }}$ & 3 & $\mathrm{~m}$ & This work \\
$\mathrm{E}_{\mathrm{B}, \mathrm{V}}$ & 2.5 & - & This work \\
$\omega$ & $1 \times 10^{-9}$ & - - & 36 \\
$\eta_{\text {free,HB }}$ & $1.5 \times 10^{-2}$ & This work \\
$\eta_{\text {pinned,HB }}$ & $3 \times 10^{-2}$ & & Th \\
\hline
\end{tabular}

major input quantity into the recrystallization simulations is the effective mobility of the recrystallization front, i.e., the grain boundary mobility. This quantity (Eq. [14]) is basically determined by three partial mobilities: (i) $M_{\text {free }}$, (ii) $M_{\text {pinned }}$, and (iii) $M_{\mathrm{SD}}$, which are discussed in more detail next.

(i) The free mobility is parameterized in accordance to the suggestion of Turnbull ${ }^{[29]}$ as

$$
M_{\mathrm{free}}=\eta_{\mathrm{free}} \cdot M_{\mathrm{TB}}=\eta_{\mathrm{free}} \cdot \frac{\omega D_{\mathrm{GB}} V_{\mathrm{m}}}{b^{2} R T},
$$

where $\eta_{\text {free }}$ is a linear pre-factor, $M_{\mathrm{TB}}$ is the Turnbull mobility, $\omega$ is the grain boundary width, and $D_{\mathrm{GB}}$ is the substitutional self-diffusion coefficient along grain boundaries. The latter is adopted from a recent independent assessment of Stechauner and Kozeschnik, ${ }^{[30]}$ providing the essential information on the temperature dependence of the free mobility, which thus becomes a fixed quantity in our treatment instead of being an unknown fitting parameter. The absolute value of this quantity is adjusted such that it is in accordance to the mobility suggestion for low-alloyed austenite reported in Reference 31 . A pre-factor of $\eta_{\text {free }}=1.5$ pct is chosen in the present work. A grain boundary width of $\omega=1 \mathrm{~nm}$ is adopted from Reference 32 .

(ii) The pinned mobility concept, as utilized in the present work, is based on the assumption of local precipitate coarsening along grain boundaries. This concept has been introduced recently in Reference 25 and it was briefly described earlier in Section II-B. In an analysis of grain boundary precipitate coarsening, Kirchner ${ }^{[33]}$ showed that coarsening at grain boundaries should obey a temperature dependence deter- mined by the grain boundary diffusion coefficient. We thus conclude that the temperature dependence of the Turnbull mobility is also determining the local coarsening kinetics. Therefore, we adopt this concept for the pinned mobility and express it as a fraction of the Turnbull mobility with

$$
M_{\text {pinned }}=\eta_{\text {pinned }} \cdot M_{\text {free }}=\eta_{\text {pinned }} \cdot \eta_{\text {free }} \cdot M_{\mathrm{TB}}
$$

with a dimensionless pre-factor, $\eta_{\text {pinned }}$. In the present work, its value is set to 3 pct.

(iii) The empirical studies by Andrade et al. ${ }^{[4]}$ show that the solute drag effect of $\mathrm{V}$ during recrystallization is considerably smaller than that of $\mathrm{Ti}$ or $\mathrm{Nb}$, however, it is supposed to be still conceivable at lower temperatures. Unfortunately, Andrade et al. do not report absolute values for the binding energy of $\mathrm{V}$ to the grain boundary within the framework of the Cahn model. ${ }^{[3]}$ We assume that the trapping energy of $\mathrm{V}$ to the austenite grain boundaries is of the order of $2.5 \mathrm{~kJ} / \mathrm{mol}$, because this value delivers good agreement with experimental evidence.

The driving pressure for recrystallization is mainly determined by the amount of excess defects (dislocations) that are introduced into the material during deformation. The dislocation density evolution is, in turn, determined by the material parameters $A, B$, and $C$ (Eq. [5]) and, in the present work, adjusted to the flow curve data of Hernandez et al. ${ }^{[34]}$ utilizing the Taylor forest hardening law. For the deformation conditions reported there and used here, the computed dislocation densities reach maximum values below $8 \times 10^{14} \mathrm{~m}^{-2}$. The parameters used in the present study are 
summarized in Table II. In a recent contribution, ${ }^{[25]}$ the basic functionality of the elaborated model has been demonstrated with similar input parameters. Both, the nucleation and growth behavior, showed reasonable agreement with experiment.

\section{RESULTS AND DISCUSSION}

In this section, we compare our simulations with the experimental data obtained by Medina and co-work$\mathrm{ers}^{[28]}$ on a series of V-micro-alloyed steels (see Table I). In the simulations, we apply the same thermo-mechanical treatment as reported in the corresponding study. To obtain information on the initial grain size for recrystallization after solution heat treatment at $1503 \mathrm{~K}$ $\left(1230{ }^{\circ} \mathrm{C}\right)$ for 600 seconds, Medina et al. ${ }^{[28]}$ utilize metallographic methods. The double-hit deformation experiments are performed as torsion tests at different temperatures ranging from $1098 \mathrm{~K}$ to $1373 \mathrm{~K}\left(825^{\circ} \mathrm{C}\right.$ and $\left.1100{ }^{\circ} \mathrm{C}\right)$. The deformation conditions are kept constant during every measurement with a strain rate of $3.63 \mathrm{~s}^{-1}$ and a strain of 0.35 . Figure 1 shows our simulation results in comparison to the experiments from Reference 28. With the single set of input parameters, we obtain excellent agreement for all three steels investigated here. For illustration of the effect of solute drag, we have computed the recrystallization kinetics at the two lowest temperatures for each alloy with and without solute drag (dashed gray lines). Although generating comprehensible and reasonable results for the solute content and temperature-dependent HAGB-mobilities, the Cahn approach ${ }^{[3]}$ represents a mean (static) solution for the solute drag impact on boundary movement, which does not consider solute enrichment at these moving grain boundaries. The predictive capability of the presented model could benefit from a transient solute drag model, such as presented by Svoboda et al. ${ }^{[35]}$ However, this has not been in the focus of the present research.

In each of the considered alloys, the recrystallized fractions exhibit distinct plateaus of recrystallization stasis, which are caused by the pinning effect of $\mathrm{V}(\mathrm{C}, \mathrm{N})$ precipitates on the moving grain boundaries. With increasing V-carbo-nitride supersaturation from alloy $\mathrm{V} 1$ to $\mathrm{V} 3$, the increasing pinning potential affects recrystallization in two ways: (i) the plateaus start at earlier times and (ii) the plateaus occur at higher testing temperatures. Both trends are well captured by the simulations and can clearly be attributed to the corresponding differences in precipitation kinetics. With increasing $\mathrm{V}$ and $\mathrm{N}$ contents, the driving force for precipitation increases and, thus, the driving pressure for recrystallization is compensated by the retarding Zener pressure at earlier times and at higher temperatures.

As soon as the Zener pressure equals the driving pressure for recrystallization, the effective grain boundary mobility is drastically reduced and a slower recrystallization kinetics is observed. Figure 2 illustrates the occurrence of these thresholds for each considered alloy by plotting the time-temperature-precipitation (TTP)
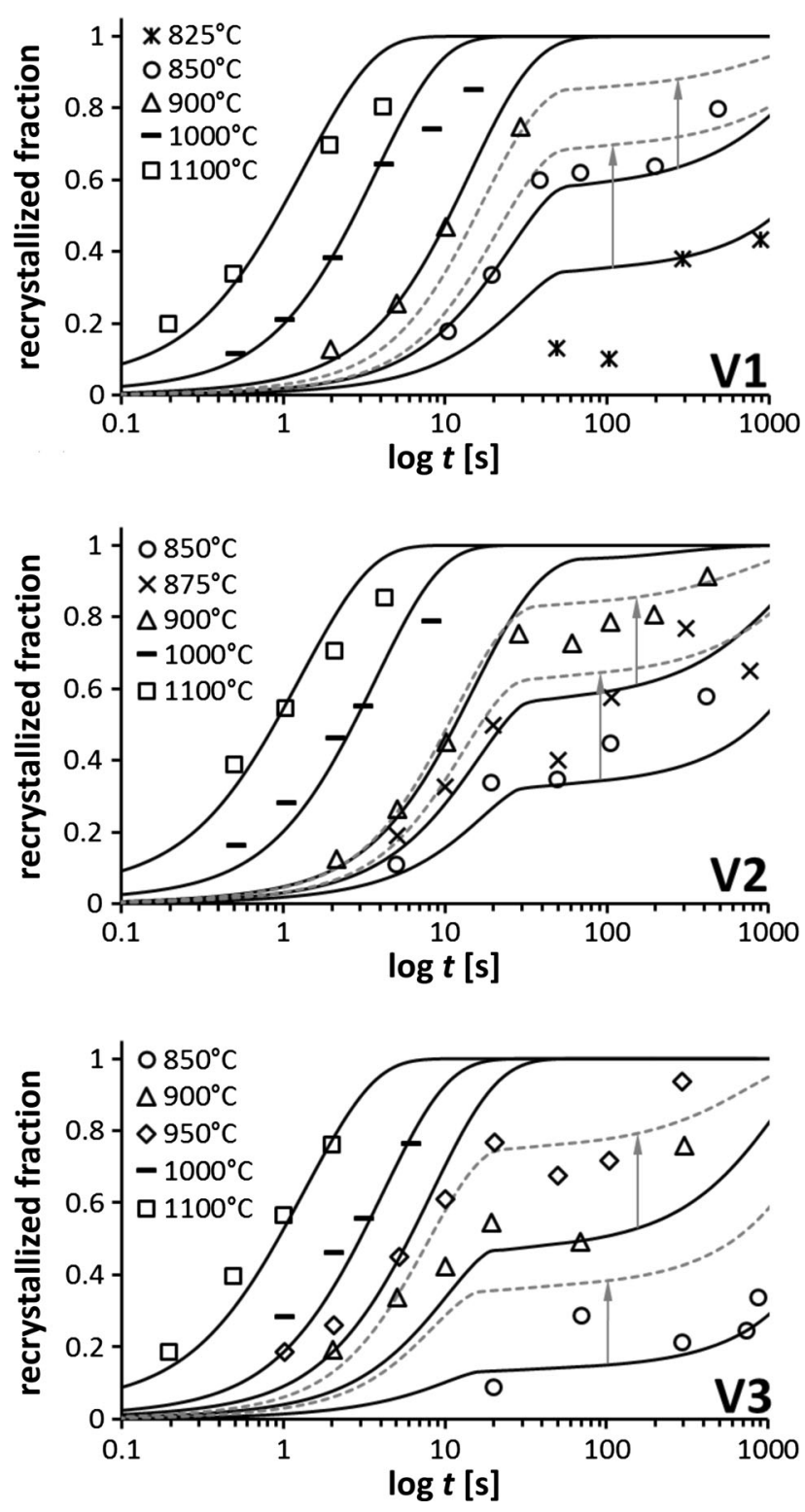

Fig. 1-Calculated and experimental recrystallization kinetics for steels V1, V2, and V3 from Ref. [28]. Dashed lines: Computed curves neglecting the solute drag effect.

kinetics for the 5 pct precipitated phase fraction lines and for the lines where $P_{\mathrm{D}}$ equals $P_{\mathrm{Z}}$. For the present set of investigated alloys, a time range within approximately a factor of four is spanned and a corresponding temperature interval of approximately $70 \mathrm{~K}\left(-203{ }^{\circ} \mathrm{C}\right)$. The precipitation simulations in Figure 2 clearly support the interpretation that the recrystallization plateaus are caused by Zener pinning, which is controversially discussed in literature.

On the one hand, Zurob et al. ${ }^{[36]}$ suggest that dislocation pinning by precipitates represents the origin of the measured plateaus. These authors argue that static recovery is severely hindered if the number density of precipitates exerts a certain limit. By virtue of a pinned dislocation network, no further energy loss and, thus, softening would be measured if a softening 

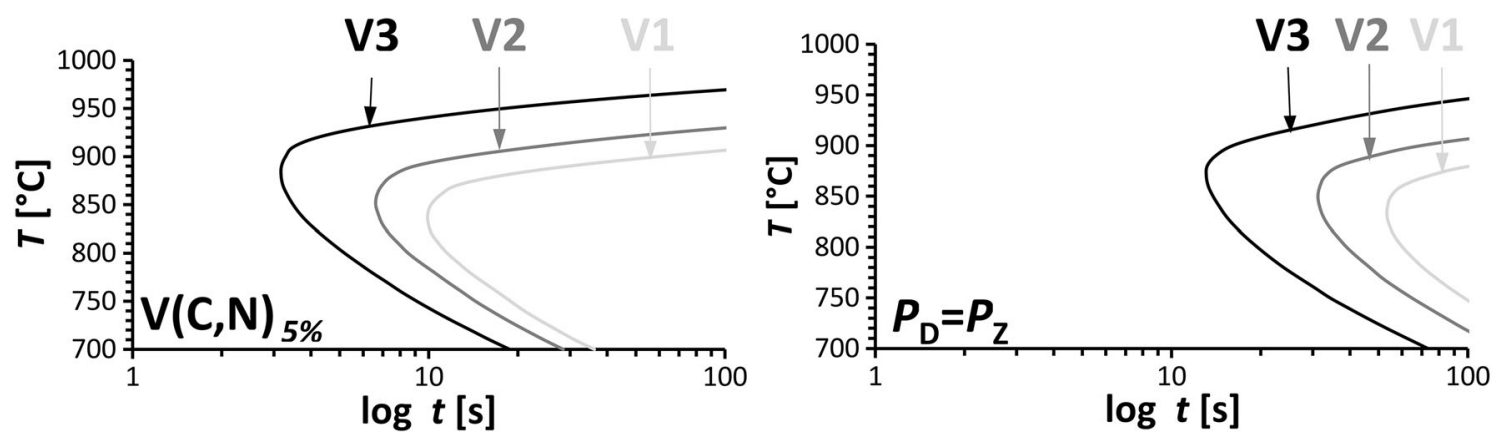

Fig. 2-Simulated TTP-curves for 5 pct precipitated fraction and the position where the driving pressure for recrystallization equals the Zener pinning pressure.

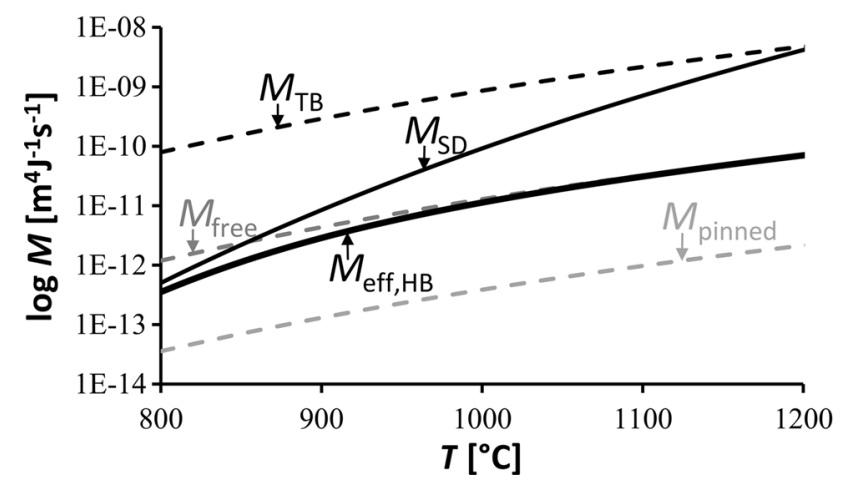

Fig. 3-Partial mobilities utilized in the simulations for alloy V3.

fraction method is used for evaluation. Consequently, if recrystallization and precipitation occur simultaneously, these authors argue that softening fraction measurements do not deliver information on the recrystallized fraction and that classic Zener pinning is not the reason for the observed plateaus. On the other hand, Medina et al. ${ }^{[37]}$ relate the observed plateaus directly to the recrystallized fraction and the interaction of recrystallization with particle pinning. These authors claim that their softening fraction data measured with the back-extrapolation method correlate well with the recrystallized fraction. To support their arguments, they analyze a substantial amount of experimental data and confirm their analysis with metallographic characterization of recrystallization at different stages during their experiments. ${ }^{[38-40]}$ In the present work, we adopt the interpretation of Medina et al., however being aware that some controversy exists in this field.

In Figure 1, the recrystallized fraction curves are calculated with and without consideration of the solute drag effect caused by V atoms. Apparently, the impact of solute drag is rather substantial at lower temperatures, whereas it appears to be negligible at higher temperatures. The calculated partial mobilities plotted in Figure 3 support this observation. The black dashed line shows the mobility suggested by the Turnbull approach, which is based on the grain boundary diffusion coefficient assessed in Reference 30. The gray dashed line denoted by $M_{\text {free }}$ represents the effective mobility of the unpinned and solute drag-free boundary. $M_{\mathrm{SD}}$ is the mobility calculated from the Cahn model,
Eqs. [11] and [12], and using a binding energy between $\mathrm{V}$ atoms and grain boundary of $2.5 \mathrm{~kJ} / \mathrm{mol}$. The effective mobility for the unpinned grain boundary, $M_{\mathrm{eff}, \mathrm{HB}}$, is deviating from $M_{\text {free }}$ only at the lowest temperatures, whereas they converge at the higher temperatures. The grain boundary mobility accounting for the pinning effect of precipitates is effective only after the driving force for recrystallization balances the Zener pressure, i.e., $P_{\mathrm{D}}$ equals $P_{\mathrm{Z}}$. Once the grain boundary is pinned by precipitates, solute drag is ineffective in the present steels under consideration.

\section{SUMMARY}

In the present work, we propose a comprehensive model for thermokinetic modeling of simultaneous recrystallization, precipitation, and solute drag. The impact of precipitation on the observed recrystallization stasis is assumed to be determined by Zener particle pinning and the kinetics of local precipitate coarsening at grain boundaries. In contrast to conventional modeling approaches, this effect is included into the mobility term instead of evaluating a threshold value for complete recrystallization stasis with zero grain boundary mobility. This consideration is essential for a consistent simulation of experimentally evidenced recrystallization plateaus. In addition to Zener pinning, the solute drag effect is incorporated in the sense of the Cahn solute drag approach. It is demonstrated that this effect has significant impact on the recrystallization kinetics at the lowest testing temperatures. We observe good agreement between simulations and experiments with a binding energy of $2.5 \mathrm{~kJ} / \mathrm{mol}$.

\section{ACKNOWLEDGMENTS}

Open access funding provided by TU Wien (TUW).

\section{OPEN ACCESS}

This article is distributed under the terms of the Creative Commons Attribution 4.0 International License (http://creativecommons.org/licenses/by/4.0/), which permits 
unrestricted use, distribution, and reproduction in any medium, provided you give appropriate credit to the original author(s) and the source, provide a link to the Creative Commons license, and indicate if changes were made.

\section{REFERENCES}

1. C.S. Smith: Trans. AIME, 1948, vol. 175, pp. 15-51.

2. M. Gomez, A. Quispe, and S.F. Medina: Steel Res. Int., 2014, vol. 85 , pp. 1440-45.

3. J.W. Cahn: Acta Metall., 1962, vol. 10, pp. 789-98.

4. H.L. Andrade, M.G. Akben, and J.J. Jonas: Metall. Trans. A, 1983, vol. 14, pp. 1967-77.

5. S.F. Medina and A. Quispe: ISIJ Int., 2001, vol. 41, pp. 774-81.

6. M. Avrami: J. Chem. Phys., 1940, vol. 8, pp. 212-24.

7. H.S. Zurob, Y. Brechet, and G. Purdy: Acta Mater., 2001, vol. 49, pp. 4183-90.

8. K. Rehman and H.S. Zurob: Mater. Sci. Forum, 2013, vol. 753, pp. 417-22.

9. M. Hillert: Acta Metall., 1965, vol. 13, pp. 227-38.

10. E. Nes: Acta Metall., 1976, vol. 24, pp. 391-98.

11. R. Radis and E. Kozeschnik: Model. Simul. Mater. Sci. Eng., 2012, vol. 20, p. 055010.

12. R. Radis and E. Kozeschnik: Model. Simul. Mater. Sci. Eng., 2010, vol. 18 , p. 055003 .

13. E. Kozeschnik, J. Svoboda, P. Fratzl, F.D. Fischer, P. Fratzl, and E. Kozeschnik: Mater. Sci. Eng. A, 2004, vol. 385, pp. 166-74.

14. B. Sonderegger and E. Kozeschnik: Metall. Mater. Trans. A, 2009, vol. 40A, pp. 499-510.

15. B. Sonderegger and E. Kozeschnik: Scr. Mater., 2009, vol. 60, pp. 635-38.

16. B. Sonderegger and E. Kozeschnik: Metall. Mater. Trans. A, 2010, vol. 41A, pp. 3262-69.

17. J.E. Bailey and P.B. Hirsch: Proc. R. Soc. Lond. A, 1962, vol. 267, pp. 11-37.

18. S.S. Hansen, J.B. Vander Sande, and M. Cohen: Metall. Trans. A, 1980, vol. 11A, pp. 387-402.
19. Y. Huang and F.J. Humphreys: Acta Mater., 2000, vol. 48, pp. 2017-30.

20. P. Sherstnev, P. Lang, and E. Kozeschnik: Eur. Congr. Comput. Methods Appl. Sci. Eng., 2012.

21. W.T. Read and W. Shockley: Phys. Rev., 1950, vol. 78, pp. $275-89$

22. Y. Estrin, L.S. Tóth, A. Molinari, and Y. Bréchet: Acta Mater., 1998, vol. 46, pp. 5509-22.

23. E. Nes: Prog. Mater. Sci., 1997, vol. 41, pp. 129-93.

24. M. Rath and E. Kozeschnik: Mater. Sci. Forum, 2013, vol. 753, pp. 357-60.

25. H. Buken, P. Sherstnev, and E. Kozeschnik: Model. Simul. Mater. Sci. Eng., 2016, vol. 24, p. 35006.

26. Y. Yazawa, T. Furuhara, and T. Maki: Acta Mater., 2004, vol. 52, pp. 3727-36.

27. A. Jones and B. Ralph: Acta Metall., 1975, vol. 23, pp. 355-63.

28. S.F. Medina, J.E. Mancilla, and C.A. Hernández: ISIJ Int., 1994, vol. 34, pp. 689-96.

29. D. Turnbull: Trans. AIME, 1951, vol. 191, pp. 661-65.

30. G. Stechauner and E. Kozeschnik: Calphad, 2014, vol. 47, pp. 92-99.

31. T. Zhou, R.J. O'Malley, and H.S. Zurob: Metall. Mater. Trans. A., 2010, vol. 41A, pp. 2112-20.

32. M.K. Rehman and H.S. Zurob: Metall. Mater. Trans. A, 2013, vol. 44A, pp. 1862-71.

33. H.O.K. Kirchner: Metall. Trans., 1971, vol. 2, pp. 2861-64.

34. C.A. Hernandez, S.F. Medina, and J. Ruiz: Acta Metall., 1996, vol. 44, pp. $155-63$.

35. J. Svoboda, F.D. Fischer, and M. Leindl: Acta Mater., 2011, vol. 59 , pp. $6556-62$.

36. H.S. Zurob, C.R. Hutchinson, Y. Brechet, and G.R. Purdy: Mater. Sci. Eng. A, 2004, vol. 382, pp. 64-81.

37. M. Gómez, L. Rancel, and S.F. Medina: Mater. Sci. Eng. A, 2009, vol. 506, pp. 165-73.

38. A. Quispe, S.F. Medina, M. Gómez, and J.I. Chaves: Mater. Sci. Eng. A, 2007, vol. 447, pp. 11-18.

39. A. Quispe, S.F. Medina, and P. Valles: ISIJ Int., 1997, vol. 37, pp. $783-88$.

40. M Gómez, SF Medina, A Quispe, and P Valles: ISIJ Int., 2002, vol. 42, pp. 423-31. 